\title{
Consequences of Dopaminergic Denervation on the Metabolic Activity of the Cortical Neurons Projecting to the Subthalamic Nucleus in the Rat
}

\author{
Gaël Orieux, ${ }^{1}$ Chantal François, ${ }^{1}$ Jean Féger, ${ }^{1,2}$ and Etienne C. Hirsch ${ }^{1}$ \\ 1/nstitut National de la Santé et de la Recherche Médicale U.289 "Neurologie et Thérapeutique Expérimentale," \\ Hôpital de la Salpêtrière, 75651 Paris Cedex 13, France, and 2Faculté des Sciences Pharmaceutiques et Biologiques, \\ Université René Descartes, Paris, 75006 France
}

Parkinsonian symptoms are currently thought to be related to hyperactivity of the subthalamic nucleus (STN). Because the STN is known to receive many inputs including glutamatergic cortical afferent fibers, we sought to determine whether the activity of this pathway is altered after dopaminergic denervation to estimate its contribution to the impairment of STN activity.

A precise mapping of the origin of the corticosubthalamic projection was first performed using retrograde and anterograde tracing methods. Cortical neurons projecting to the STN were found to originate in layer $\mathrm{V}$ of the motor, anterior cingulate, and dorsal insular cortices, and the most anterior tip of the frontal lobe, leading to different functional corticosubthalamic inputs. The metabolic activity of the neurons projecting to the STN, first identified by retrograde tracing, was then evaluated by in situ hybridization of the first subunit of cytochrome oxidase (COI), a marker of metabolic activity, in unilateral 6-hydroxydopamine-lesioned rats. Measurements of COI mRNA expression showed a 38 and $41.5 \%$ decrease after dopaminergic denervation in the neurons projecting to the STN located in the motor and dorsal insular areas, respectively, whereas neuronal activity was mildly changed in neurons of the anterior cingulate cortex.

The modified activity of STN neurons in parkinsonism may thus result in part from complex interactions between glutamatergic hyperactive fibers originating in the thalamus and the pedunculopontine nucleus and hypoactive fibers originating in the cerebral cortex.

Key words: subthalamic nucleus; cerebral cortex; Parkinson's disease; dopamine; neuronal tracing; cytochrome oxidase
Within the basal ganglia, the subthalamic nucleus (STN) plays a critical role in the control of movement, exerting a powerful excitatory influence on both segments of the globus pallidus and the substantia nigra pars reticulata $(\mathrm{SNc})$. Under pathological conditions, a hyperactivity of the STN plays a major role in the pathophysiology of Parkinson's disease (Bergman et al., 1994; Hassani et al., 1996; Hutchison et al., 1998; Magnin et al., 2000). Manipulation of STN neuronal activity has emerged as a promising therapeutic approach for Parkinson's disease. Indeed, suppressing its hyperactivity in Parkinson's disease by high-frequency stimulation or lesion has been shown to strongly alleviate parkinsonian symptoms in patients with idiopathic Parkinson's disease and in 1-methyl-4-phenyl-1,2,3,6-tetrahydropyridine-intoxicated monkeys (Bergman et al., 1990; Benazzouz et al., 1993; Limousin et al., 1995; Guridi et al., 1996).

On the basis of the classical model of basal ganglia circuitry (Albin et al., 1989; DeLong, 1990) obtained using electrophysiological recordings and 2-deoxyglucose measurements, it has been suggested that the strong hyperactivity of the STN in Parkinson's disease could be caused by a decrease in the inhibitory influence

Received March 20, 2002; revised July 2, 2002; accepted July 15, 2002.

This study was supported by Institut National de la Santé et de la Recherche Médicale and the National Parkinson Foundation, Miami. G.O. was supported by a grant from Fondation France Parkinson (2000) and Fondation pour la Recherche Médicale (2001). We thank Dr. P. Gaspar for her helpful advice.

Correspondence should be addressed to Dr. E. C. Hirsch, Institut National de la Santé et de la Recherche Médicale U.289 "Neurologie et Thérapeutique Expérimentale," Hôpital de la Salpêtrière, 47 boulevard de l'Hôpital, 75651 Paris Cedex 13, France. E-mail: hirsch@ccr.jussieu.fr.

Copyright (ㄷ) 2002 Society for Neuroscience $0270-6474 / 02 / 228762-09 \$ 15.00 / 0$ of the external segment of the globus pallidus (GPe). However, biochemical metabolic and electrophysiological recording after lesion of this nucleus suggests that the hyperactivity of the STN is not caused solely by hypoactivity of the GPe (Soghomonian and Chesselet, 1992; Hassani et al., 1996; Herrero et al., 1996; Vila et al., 1997). More recent models of basal ganglia organization have pointed to the fact that the STN receives other afferent fibers that had initially been neglected. In addition to the well known inhibitory pallidal afferent pathway (Nauta and Mehler, 1966; Smith et al., 1990), the STN receives monoaminergic inputs from the dorsal raphe nuclei (Mori et al., 1985; Canteras et al., 1990; Lavoie and Parent, 1990) and the SNc (Hassani et al., 1997; Hedreen, 1999; François et al., 2000), and excitatory inputs from the pedunculopontine nucleus (Jackson and Crossman, 1983; Lavoie and Parent, 1994; Bevan and Bolam, 1995), the parafascicular nucleus of the thalamus (Sugimoto et al., 1983; Féger et al., 1994; Mouroux et al., 1995), and the cerebral cortex in primates (for review, see Parent and Hazrati, 1995; Smith et al., 1998) and in rats (Kitai and Deniau, 1981; Afsharpour, 1985; Rouzaire-Dubois and Scarnati, 1987; Canteras et al., 1988; Berendse and Groenewegen, 1991; Fujimoto and Kita, 1993; Bevan et al., 1995; Maurice et al., 1998).

Little is known about the status of these projections in the parkinsonian state. We recently showed that excitatory parafascicular and pedunculopontine projections to the STN both displayed a metabolic hyperactivity, supporting a role of these structures in the hyperactivity of the STN after dopaminergic denervation (Orieux et al., 2000). Yet, cortical afferent fibers to the STN are also thought to represent a major excitatory input to 


\begin{tabular}{|c|c|c|c|c|}
\hline & Cerebral structure & Anteriority (mm) & Laterality $(\mathrm{mm})$ & Depth (mm) \\
\hline Fluoro-Gold & Subthalamic nucleus & -3.2 & \pm 2.5 & -7.7 \\
\hline \multirow[t]{3}{*}{ BDA } & Somatosensory cortex & +1.0 & \pm 4.5 & -3.2 \\
\hline & Anterior cingular cortex & +3.5 & \pm 0.5 & -3.0 \\
\hline & Dorsal insular cortex & +2.0 & \pm 5.0 & -4.5 \\
\hline
\end{tabular}

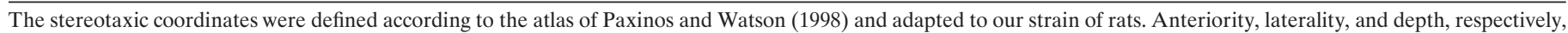
are defined in relation to the bregma, the midline, and the surface of the brain. BDA, Biotin dextran amine.

the STN, but their status in parkinsonism is unknown. Thus, we investigated this projection in a rodent model of Parkinson's disease by measuring the expression of the first subunit of cytochrome oxidase (COI), an index of metabolic activity (WongRiley, 1989; Hevner and Wong-Riley, 1993) in retrogradely identified corticosubthalamic neurons.

\section{MATERIALS AND METHODS}

Experimental cases. Thirty-eight adult male Sprague Dawley rats weighing 250-300 gm (CERJ, Le Genest St. Isle, France) were used in the study. Twenty-six animals were used to study the metabolic activity of the corticosubthalamic neurons. Twelve animals were used for the anatomical aspects of the study using Fluoro-Gold (FG) or biotinylated dextran amine (BDA) injections. The animals were housed under constant temperature and humidity conditions on a $12 \mathrm{hr}$ light/dark cycle with ad libitum access to food and water. Lesion and injection procedures were performed under general anesthesia with ketamine $(50 \mathrm{mg} / \mathrm{kg}$, Imalgène 500 ; Merial, Lyon, France) and xylazine (10 mg/kg, Rompun $2 \%$; Bayer, Leverkusen, Germany) administered intramuscularly. All injections (neuronal tracer or lesioning solution) were realized under stereotaxic guidance with the top of the skull in the horizontal position and the incisor bar $3.3 \mathrm{~mm}$ below the interaural line (Horsley Clark apparatus, Unimécanique, Paris, France). The coordinates were defined according to the atlas of the rat brain of Paxinos and Watson (1998) and adapted to our strain of rats. All of the animals were killed by an intraperitoneal lethal injection $(4 \mathrm{ml} / \mathrm{kg}$ ) of $6 \%$ sodium pentobarbital (Sanofi) followed by intracardiac perfusion. Every effort was made to keep the number of animals to a minimum and to minimize suffering; all experiments were performed in accordance with the Declaration of Helsinki and the Guide for the Care and Use of Laboratory Animals as adopted and promulgated by National Institutes of Health (Bethesda, MD).

Anatomical tracing methods. FG (Fluorochrome Inc; Denver, CO), a retrogradely transported tracer, was injected into the STN, and BDA (Sigma, St. Louis, MO), an anterogradely transported tracer, was injected into different areas of the cerebral cortex (motor, somatosensory, prefrontal, and dorsal insular cortex). FG (4\% in $\mathrm{NaCl} 0.9 \%$ ) or BDA ( $10 \%$ in phosphate buffer $0.01 \mathrm{M}$ ) was placed in a glass microelectrode with a tip diameter of $\sim 30-40 \mu \mathrm{m}$ and injected iontophoretically. The injection parameters were a current of 4 and $6 \mu \mathrm{A}$ delivered in $7 \mathrm{sec}$ pulses at $7 \mathrm{sec}$ intervals and $7 \mathrm{sec}$ pulses at $9 \mathrm{sec}$ intervals for 20 and 25 min for FG and BDA, respectively. The stereotaxic coordinates used for the different targets are reported in Table 1 . After a survival period of $7 \mathrm{~d}$ for the animals that received an FG injection and $10 \mathrm{~d}$ for those that received a BDA injection, the rats were killed and transcardially perfused with $250 \mathrm{ml}$ of a heparin solution $5 \mathrm{UI} / \mathrm{ml}$ in $\mathrm{NaCl} 0.9 \%$ at $37^{\circ} \mathrm{C}$ followed by $350 \mathrm{ml}$ of a $4 \%$ paraformaldehyde solution in $0.1 \mathrm{M}$ phosphate buffer at $4^{\circ} \mathrm{C}$, and then $200 \mathrm{ml}$ of a $10 \%$ sucrose solution in phosphate buffer at $4^{\circ} \mathrm{C}$, with $4 \%$ paraformaldehyde added for FGinjected brains only. Brains were then removed from the skull and immersed in $0.1 \mathrm{~m}$ phosphate buffer containing $10 \%$ sucrose (BDAinjected brains) or $10 \%$ sucrose and $4 \%$ paraformaldehyde (FG-injected brains) for $10 \mathrm{hr}$, and then $24 \mathrm{hr}$ in the same solution with $20 \%$ sucrose (both BDA- and FG-injected brains). Brains were frozen in isopentane $\left(-40^{\circ} \mathrm{C}\right)$ and cut into coronal $50-\mu \mathrm{m}$-thick sections on a freezing microtome (Reichert-Jung, Heidelberg, Germany). BDA sections were conserved in $0.1 \mathrm{M}$ PBS with $0.1 \%$ sodium azide added.

To visualize FG, sections were immediately mounted onto gelatincoated slides, dried, coverslipped with mounting medium for fluorescence (Vectashield, Vector Laboratories, Burlingame, CA), and observed under a fluorescence microscope (Ultraviolet filter BP, $\lambda=365$ $\mu \mathrm{m})$. All manipulations of FG-labeled sections were performed in darkness. FG-labeled neurons were plotted by computer-assisted image analysis (Visioscan, Biocom, Les Ulis, France), and thereafter the sections were counterstained with cresyl violet.

BDA was revealed using the avidin-biotin complex method as described elsewhere (Gown et al., 1986; Veenman et al., 1992). After abundant rinses in $0.1 \mathrm{M}$ PBS, sections were permeabilized for $90 \mathrm{~min}$ in 0.1 M PBS containing $1 \%$ Triton X-100 and then incubated in the avidin-biotin complex (ABC Kit Elite Vectastin, Vector Laboratories) diluted 1:100 in $0.1 \mathrm{M}$ PBS including $1 \%$ Triton for $24 \mathrm{hr}$ at room temperature. Sections were rinsed in $0.1 \mathrm{M}$ acetate buffer, $\mathrm{pH} 6$, and the BDA was revealed in a solution of $0.1 \mathrm{M}$ acetate buffer containing $0.02 \%$ 3,3'-diaminobenzidine tetrahydrochloride (Sigma), $2.5 \%$ nickel sulfate, $0.2 \%$ D-glucose, $0.04 \%$ ammonium chloride, and $0.0025 \%$ glucose oxidase (Sigma). The reaction was stopped by repeated washes in acetate buffer. Sections were finally mounted on gelatin-coated slides, dehydrated in graded alcohol, delipidated in xylene, and coverslipped with Eukitt (O. Kindler GmbH \& Co., Freiburg, Germany). Some sections were counterstained with a $0.25 \%$ green methyl solution (Fluka Chemica, AG, Buchs, Switzerland).

Unilateral lesion of dopaminergic neurons of the substantia nigra by 6-hydroxydopamine. Rats were pretreated $30 \mathrm{~min}$ before intranigral injection of 6-hydroxydopamine (6-OHDA) with $25 \mathrm{mg} / \mathrm{kg}$ of desipramine hydrochloride (Sigma) and $50 \mathrm{mg} / \mathrm{kg}$ of pargyline (Sigma) to protect noradrenergic neurons and inhibit monoamine oxidase, respectively. A stainless steel cannula, outer diameter of $0.3 \mathrm{~mm}$, linked to a catheter was connected to a microsyringe (10 $\mu$ l airtight; Hamilton). The cannula was placed in the substantia nigra, under stereotaxic guidance, $5.2 \mathrm{~mm}$ posterior to the bregma, $1.8 \mathrm{~mm}$ lateral to the midline, and $7.7 \mathrm{~mm}$ below the dura (Paxinos and Watson, 1998), and $2 \mu$ l of 6-OHDA solution (4 $\mu \mathrm{g} / \mu \mathrm{l}$ in a $0.01 \%$ ascorbic acid solution; Sigma) was infused by the pressure method over a 5 min period using an infusion pump (Precidor Infors AG, Basel, Switzerland). Control rats received the same pretreatment and an injection of the vehicle $(0.01 \%$ ascorbic acid solution) into the substantia nigra, following the same procedure as for the 6-OHDAlesioned rats.

Assessment of the nigral lesion. Analysis of the nigral lesion was performed by immunoautoradiography of the dopamine transporter in the striatum, as described previously (Naudon et al., 1996). Briefly, unfixed slide-mounted sections were dried for $3 \mathrm{hr}$, treated in a solution of $1 \%$ bovine serum albumin and $1 \%$ normal goat serum in $0.1 \mathrm{~m}$ PBS, and then incubated in a rabbit antibody solution directed against the dopamine transporter (provided by B. Giros, Institut National de la Santé et de la Recherche Médicale U513, Creteil, France) at a concentration of 1:20,000 for $24 \mathrm{hr}$, rinsed in $0.1 \mathrm{M} \mathrm{PBS}$, and incubated in anti-rabbit $\left[{ }^{35} \mathrm{~S}\right]$ solution at a concentration of 1:100 (initial concentration, $20 \mu \mathrm{g} / \mathrm{ml}$; specific activity, 200-700 Ci/mmol; Amersham Biosciences, Arlington Heights, IL) for $2 \mathrm{hr}$. Sections were then rinsed in $0.1 \mathrm{M}$ PBS followed by distilled water. After air drying, sections were exposed to $x$-ray film (Hyperfilm $\beta$-max; Amersham Biosciences) for 2 or $3 \mathrm{~d}$ at room temperature in light-proof boxes.

The dopaminergic lesion was estimated by quantification of striatal dopamine transporter radioimmunolabeling from the autoradiograms, as described previously (Blanchard et al., 1995).

Wheat germ agglutinin conjugated to horseradish peroxidase injection. One week after the substantia nigra lesion, wheat germ agglutinin conjugated to horseradish peroxidase (WGA-HRP) was injected under stereotaxic conditions ( $10 \%$ in $0.1 \mathrm{M}$ PBS; Sigma) into the STN ipsilateral to the operated side in both 6-OHDA-lesioned and sham-lesioned animals, as described previously (Orieux et al., 2000). Briefly, the solution was placed in a glass microelectrode with a tip diameter of $20-30 \mu \mathrm{m}$ and 
injected using an iontophoretic procedure $(5 \mu \mathrm{A}$ current delivered during $20 \mathrm{~min}, 7 \mathrm{sec}$ on $/ 7 \mathrm{sec}$ off) into the STN (stereotaxic coordinates: 3.2 $\mathrm{mm}$ posterior to the bregma, $2.5 \mathrm{~mm}$ lateral to the midline, and $7.7 \mathrm{~mm}$ below the dura) (Paxinos and Watson, 1998). The animals were killed after a $3 \mathrm{~d}$ survival time, that is to say $10 \mathrm{~d}$ after the nigral lesion, and perfused intracardially with a heparin solution $(10 \mathrm{U} / \mathrm{ml}$ in a $0.9 \% \mathrm{NaCl}$ solution at $37^{\circ} \mathrm{C}$ ). Brains were removed and frozen in cold isopentane $\left(-40^{\circ} \mathrm{C}\right)$. Frontal sections $(20 \mu \mathrm{m}$ thick) were cut using a cryostat, mounted on gelatin double-coated slides, and stored at $-80^{\circ} \mathrm{C}$ until use.

$W G A-H R P$ revelation. WGA-HRP was revealed using the method described previously (Orieux et al., 2000), as adapted from the method described by Mesulam (1978). Briefly, slides were postfixed in a $3 \%$ paraformaldehyde solution for $5 \mathrm{~min}$ and abundantly rinsed in $0.1 \mathrm{M}$ PBS and then in acetate buffer. Preincubation was performed in $0.1 \%$ sodium nitroferricyanide (Sigma) and $0.005 \%$ 3,3-5,5 tetramethyl-benzidine (Sigma) solution for $15 \mathrm{~min}$, and hydrogen peroxide was added at a concentration of $0.02-0.04 \%$ for $\sim 30-60 \mathrm{~min}$. All stages were performed at $4^{\circ} \mathrm{C}$ and in darkness.

To verify the injection site in the STN, WGA-HRP was revealed on regularly spaced sections (200-400 $\mu \mathrm{m}$ apart) for each experimental case. All of these sections were then counterstained with green methyl solution $(0.25 \%)$ for $2-3 \mathrm{~min}$ at $4^{\circ} \mathrm{C}$, rinsed in cold acetate buffer, quickly dehydrated in graded ethanol solutions, delipidated in xylene, and coverslipped with Eukitt. Only experimental cases in which the injection site was centered in the STN were selected.

Sections adjacent to those that contained labeled neurons in the structures of interest (i.e., anterior cingulate, motor, and dorsal insular cortex) were first revealed for WGA-HRP and coverslipped with nonpermanent medium, and the labeled neurons were plotted by computerassisted image analysis (Visioscan, Biocom). After analysis, the coverslip was removed in buffer, and the sections were dried for a few seconds in absolute alcohol and stored at $4^{\circ} \mathrm{C}$ until in situ hybridization was performed.

In situ hybridization. In situ hybridization with a $\left[{ }^{35} \mathrm{~S}\right]$-labeled cRNA probe was performed as described previously (Vila et al., 1997). A cRNA probe was synthesized from a double-stranded DNA fragment, corresponding to nucleotide 5308-6218 of the rodent mitochondrial genome (EMBO databank, reference MIRNXX) within the gene coding for COI, produced by PCR, and subcloned in the pGME-T vector (Promega, Madison, WI). Sense and antisense probes were transcribed from $1 \mu \mathrm{g}$ of plasmid.

Sections were rinsed for $3 \mathrm{~min}$ in $0.1 \mathrm{M}$ PBS, acetylated with $0.25 \%$ acetic anhydride in $0.1 \mathrm{~mm}$ ethanolamine, treated by $0.1 \mathrm{M}$ Tris/glycine for $30 \mathrm{~min}$, and dehydrated through graded ethanol solutions. For subthalamic nucleus sections only, this first stage was preceded by a slight fixation in a paraformaldehyde solution (3\% in PBS $0.1 \mathrm{M}$ ) for $5 \mathrm{~min}$. Sections were incubated for $3.5 \mathrm{hr}$ at $50^{\circ} \mathrm{C}$ in a humid chamber of hybridization solution containing either the antisense or the sense $\left[{ }^{35} \mathrm{~S}\right]$ labeled cRNA probe $\left(2.5 \times 10^{6} \mathrm{cpm}\right)$. After hybridization, sections were washed at $50^{\circ} \mathrm{C}$ in $50 \%$ formamide $/ 2 \times \mathrm{SSC}$, incubated for $30 \mathrm{~min}$ at $37^{\circ} \mathrm{C}$ with RNase A $(100 \mu \mathrm{g} / \mathrm{ml}$ in $2 \times$ SSC $)$ to digest unhybridized probe, rinsed again at $50^{\circ} \mathrm{C}$ in $50 \%$ formamide $/ 2 \times \mathrm{SSC}$, and then washed overnight at room temperature. After a final rinse in $2 \times \mathrm{SSC}$, the sections were dehydrated in graded ethanol solutions prepared with 300 $\mathrm{mm}$ ammonium acetate, delipidated in xylene, dehydrated in ethanol 100, and air dried. The sections were dipped in NTB-2 emulsion (Kodak, Integra Biosciences), diluted 1:2, air-dried, and stored at $4^{\circ} \mathrm{C}$ in lightproof boxes for 1-2 weeks. Autoradiograms were generated by exposing the slide to $x$-ray films (Hyperfilm $\beta$-max, Amersham Biosciences) for $2-4 \mathrm{~d}$ at $4^{\circ} \mathrm{C}$. Exposed slides were developed in Kodak D-19 for 4 min at $15^{\circ} \mathrm{C}$ and counterstained with $0.1 \%$ hematoxylin to localize cell nuclei.

Data analysis. The analysis was performed in the anterior cingulate, motor, and dorsal insular cortex on WGA-HRP retrogradely labeled cell bodies. Because in situ hybridization washed out all WGA-HRP labeling, maps generated from WGA-HRP-stained material were used to identify the retrogradely labeled neurons on in situ hybridization sections. Results were quantified by computer-assisted image analysis (Visioscan, Biocom). The expression level of COI mRNA was analyzed on a minimum of 20 neurons for each experimental case and in each cerebral cortical area. The number of silver grains over the neuronal cell bodies was estimated under polarized light by measuring optical density with respect to a standard curve of a defined number of silver grains. Grain density was then calculated. Nonspecific labeling was estimated with sense probes. The mean density of silver grains overlying the retrogradely labeled neurons was calculated for each case and in each ana- tomical region. Statistical analysis was performed using an unpaired $t$ test or a nonparametric test (test of Mann-Whitney and Wilcoxon) if the normality or equal variance test failed (SigmaStat). Tests were performed taking as factor the status of the animals (6-OHDA lesioned or sham lesioned). The null hypothesis was rejected for an $\alpha$ risk of 0.05 . Because different experimental units were lacking, according to the functional areas analyzed, we could not (1) perform a global analysis by global ANOVA or (2) compare the level of COI mRNA expression between the different areas.

\section{RESULTS}

Anatomical aspects of the corticosubthalamic pathway

The FG injection sites were centered in the STN of seven experimental cases (Fig. 1). One experimental case presented an injection centered in the zona incerta. When the injection site was centered in the STN, the tracer extended very slightly beyond the STN, in the zona incerta dorsally, the lateral part of the hypothalamus medially, and the cerebral peduncle ventrally. All of the retrogradely labeled neurons were located ipsilaterally to the injected subthalamic nucleus except for the pedunculopontine nucleus, which was labeled bilateraly. FG-labeled neurons were seen in the globus pallidus (equivalent in rodents to the GPe in primates) (Fig. 1), the SNc, and the parafascicular nucleus of the thalamus. In six cases, the globus pallidus was labeled in its whole extent. In addition, FG-labeled neurons were seen in various areas of the cerebral cortex (Fig. 1), such as the anterior cingulate, the motor and the dorsal insular cortices, and the most anterior portion of the cerebral cortex, the frontal associative area (Paxinos and Watson, 1998). In one case, which presented a small injection restricted to the medial part of the STN, an absence of retrograde labeling was noted in the dorsolateral part of the globus pallidus and in the motor cerebral cortex. A few labeled neurons were also observed in the somatosensory cortex. Whatever the cortical region analyzed, staining with cresyl violet of FG-containing sections revealed that the FG-positive neurons were localized in layer $\mathrm{V}$ of the cerebral cortex.

Because the presence of FG-labeled neurons in the cerebral cortex could be caused in part by a retrograde transport from the zona incerta or the hypothalamus, the existence of these projections was confirmed using anterograde tracing studies. Injections of BDA were made in the somatosensory cortex (data not shown), the anterior cingulate cortex, and the dorsal insular cortex (Fig. 2). When BDA was injected into the anterior cingulate cortex, scattered BDA-positive fibers were detected in the medial part of the STN almost throughout its anteroposterior extent. Anterograde labeling was also present in the STN when the tracer was injected into the dorsal insular cortex (Fig. 2). In this case, the density of BDA-positive fibers was weaker than in the previous case. Labeled fibers were restricted to the most anterior portion of the STN occupying the whole mediolateral extent, with a shift, more caudally, to a dorsal localization. In contrast, when the injection was situated in the somatosensory cortex, labeled fibers were not observed in the STN but in the ventral zone of the zona incerta.

\section{Consequence of dopaminergic denervation on subthalamic COI mRNA expression}

Twenty-six animals received successively an injection of 6-OHDA $(n=13)$ or vehicle $(n=13)$ into the SNc and of WGA-HRP into the ipsilateral STN. One 6-OHDA-lesioned animal died during the period after surgery. The animals were killed $10 \mathrm{~d}$ after the nigral lesion, and dopaminergic denervation was controlled in sham-lesioned and 6-OHDA-lesioned rats by immunoautoradiography of the dopaminergic transporter and 

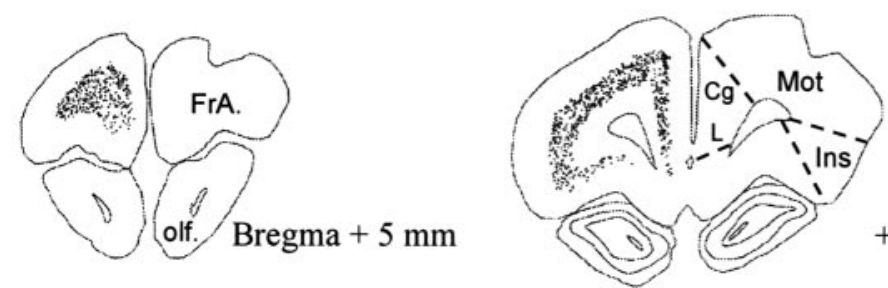

$+3.5 \mathrm{~mm}$
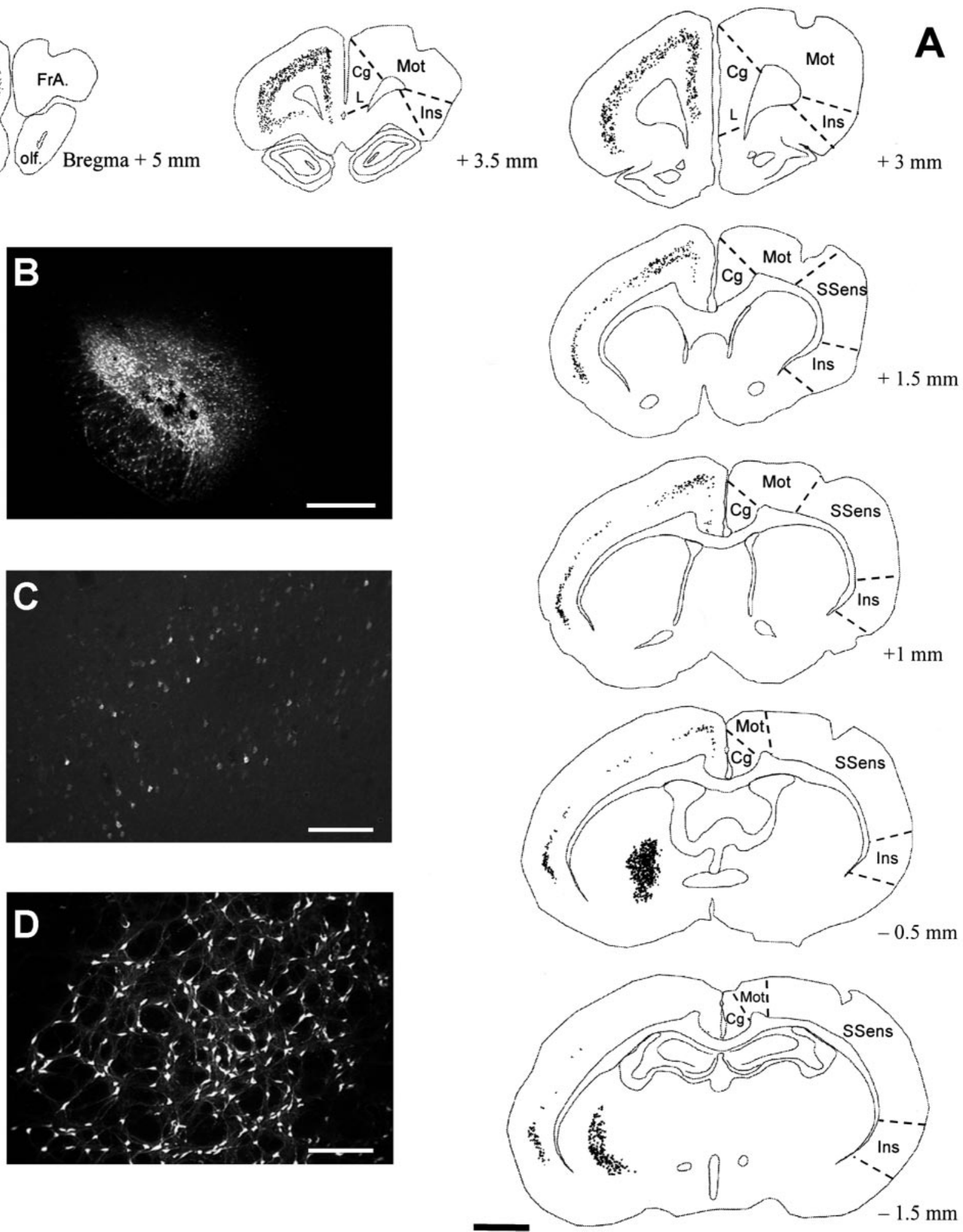

Figure 1. Afferent neurons to the STN identified by retrograde tracing. $A$, Computer-generated cartography of FG-positive neurons on seven anteroposterior levels. Each dot represents an FG-positive cell body. Structures and cortical areas were named according to the atlas of Paxinos and Watson (1998). B, Photomicrograph of an FG injection in the STN. Note the slight tissue damage indicative of the injection center. $C$, $D$, Photomicrographs of retrogradely labeled cell bodies in the cerebral cortex and the globus pallidus, respectively. $\mathrm{Cg}$, Cingulate cortex; $\mathrm{Fr} A$., frontal associative cortex; Ins, insular cortex; $L$, limbic cortex; Mot, motor cortex; olf., olfactory bundle; SSens, somatosensory cortex. Scale bars: $A, 2$ mm; $B$, 500 $\mu \mathrm{m} ; C, D, 200 \mu \mathrm{m}$. 



Figure 2. Photomicrographs of BDA injection in the cerebral cortex and BDA-positive axons in the STN. $A$, Injection of BDA in the ventral part of the cingulate cortex. $B$, Injection of BDA in the dorsal insular cortex. $C$, BDA-positive axons in the STN after BDA injection in the insular cortex. The photomicrograph has been obtained by assembly of three different photomicrographs of the same axon at a different focus. Scale bars: $A, B, 1 \mathrm{~mm} ; C, 10 \mu \mathrm{m}$.

then quantified by radioimmunolabeling. No differences in striatal labeling were observed between the operated and contralateral side of sham-lesioned animals. The quantification of radioimmunolabeling level in the striatum on the operated side showed a $62 \%$ decrease (Mann-Whitney; $p<0.001$ ) (Table 2) in the 6-OHDA-lesioned group compared with the sham-lesioned group. One experimental case presented only a $38 \%$ decrease compared with the mean of the sham-lesioned group and was excluded from the study.
The expression of COI mRNA in the STN of these animals was also measured by in situ hybridization. In subthalamic neurons on the operated side, the expression of COI mRNA was significantly increased $(+27 \% ; t$ test; $p<0.05)$ (Table 2$)$ in 6-OHDA-lesioned animals compared with sham-lesioned animals.

\section{COI mRNA expression in corticosubthalamic neurons identified by WGA-HRP tracing}

Sixteen experimental cases (8 in each group) showed a WGAHRP injection centered in the STN without excessive extent beyond the nucleus. The others, in which the injection site extended too far into adjacent structures, were excluded from the study. After exclusion of the experimental case that presented inadequate dopaminergic denervation (see the previous section), a total of seven 6-OHDA-lesioned and eight sham-lesioned animals were included in the final stages of the study. The pattern of WGA-HRP-positive neurons was similar to that observed after FG injection, even if the density of labeled neurons was markedly lower. Nevertheless, because of the restricted location of the tracer injection, the number of retrogradely labeled neurons was too small in some cortical areas $(n<20)$ to be analyzed in all experimental cases.

After in situ hybridization of COI mRNA on the same section, a specific and reproducible pattern of hybridization was obtained in the cerebral cortex with the antisense probe. No differences in COI mRNA expression were observed between the different cortical areas analyzed (i.e., anterior cingulate, motor, and dorsal insular cortices) in the sham-lesioned group. Silver grain clusters detected at the cellular level overlapped neuronal cell bodies seen with hematoxylin counterstaining. A quantitative analysis of COI mRNA expression in retrogradely labeled neurons was performed at one anteroposterior level that included the anterior cingulate, motor, and dorsal insular cortices (Fig. $1 \mathrm{~A}$, bregma +3 $\mathrm{mm})$.

COI mRNA expression was measured at the cellular level only on cell bodies stained previously for WGA-HRP and identified using computer-generated maps (Fig. 3). Ten days after the dopaminergic denervation, COI mRNA expression was decreased in the motor cortex $(-38 \%$; $t$ test; $p<0.01)$ (Table 2$)$. A similar decrease was found in the dorsal insular cortex in 6-OHDA-lesioned rats $(-41.5 \%$; $t$ test; $p<0.05)$ (Table 2$)$. In the anterior cingulate cortex, COI mRNA expression tended to be decreased in 6-OHDA-lesioned animals, even if the difference was not statistically significant $(-13 \%)$ (Table 2$)$. Some neurons stained previously with WGA-HRP were not analyzed after in situ hybridization because their silver grain density did not reach twice the background density and were thus considered as unlabeled. To determine whether the proportion of such neurons was changed after dopaminergic denervation, we compared their proportion between sham-lesioned and 6-OHDA-lesioned rats. No difference between the two groups of animals was observed whatever the region analyzed $(9.6 \pm 6.6 \%$ in the sham group and $11.3 \pm 14 \%$ in the 6 -OHDA group).

\section{DISCUSSION}

The aim of the present study was to determine whether the activity of the corticosubthalamic neurons is altered after dopaminergic denervation. An essential prerequisite was to determine whether the cortical neurons that were analyzed actually project to the STN. Indeed, in the literature, some cortical areas have been clearly demonstrated to project to the STN, whereas others have only been suggested. 
Table 2. Changes in COI mRNA expression in corticosubthalamic neurons $10 \mathrm{~d}$ after 6-OHDA injection

Estimated COI mRNA expression (density of silver grains)

\begin{tabular}{lcllll} 
Group & DAT & STN & Ant. cing. ctx & Mot. ctx & Dor. ins. ctx \\
\hline Sham lesioned $(n=8)$ & $1 \pm 0.076$ & $0.86 \pm 0.07$ & $0.78 \pm 0.05(n=6)$ & $0.87 \pm 0.04(n=8)$ & $0.84 \pm 0.1(n=5)$ \\
6-OHDA lesioned $(n=7)$ & $0.38 \pm 0.03^{a}$ & $1.09 \pm 0.09^{b}$ & $0.68 \pm 0.12(n=5)$ & $0.54 \pm 0.08(n=5)^{c}$ & $0.49 \pm 0.1(n=5)^{b}$ \\
\hline
\end{tabular}

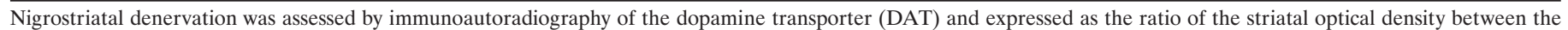



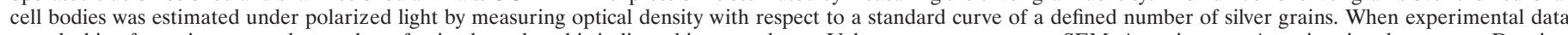

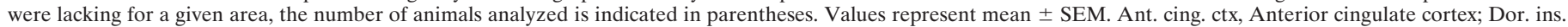
ctx, dorsal insular cortex; Mot. ctx, motor cortex.

${ }^{a} p<0.001$.

${ }^{b} p<0.05$.

${ }^{c} p<0.01$.
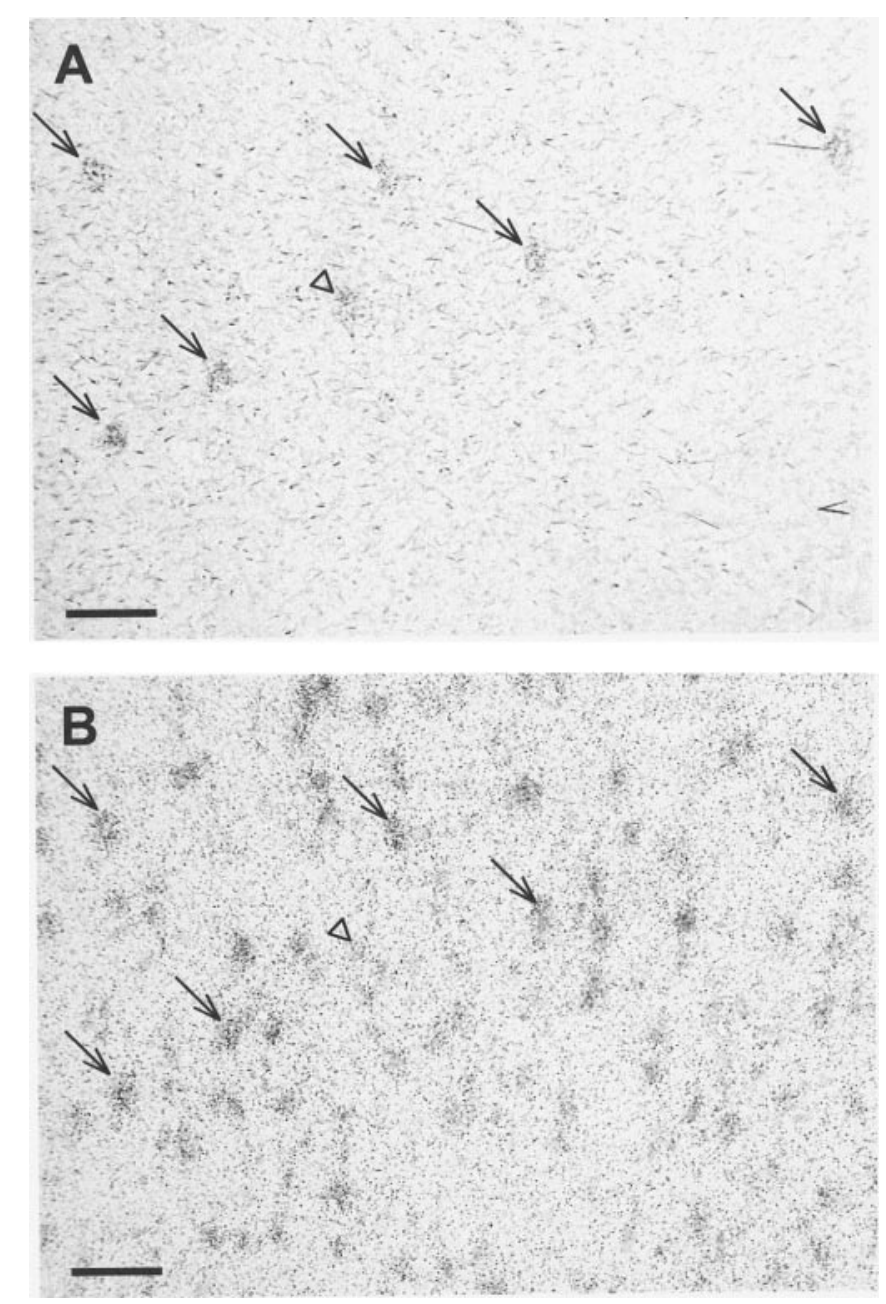

Figure 3. Photomicrographs of cell bodies successively labeled by WGAHRP revelation $(A)$ and COI in situ hybridization $(B)$. Both photomicrographs are viewed under transmitted light. The small black dots visible in $B$ correspond to silver grains. Arrows show neurons labeled successively by WGA-HRP revelation and $\mathrm{COI}$ in situ hybridization. The open arrowhead illustrates a WGA-HRP-positive neuron $(A)$ for which the in situ hybridization signal was insufficient to be counted $(B)$ and was thus considered as a COI-"negative" neuron. Scale bar, $150 \mu \mathrm{m}$.

\section{Functional anatomy of the corticosubthalamic pathway}

The first part of the study provides a precise mapping of the origin of the corticosubthalamic pathway. This analysis was first performed using a retrograde tracer injected into the STN. Be- cause the tracer could have been taken up by structures adjacent to the STN (i.e., zona incerta and hypothalamus) and by fibers of passage, the connections were then confirmed by anterograde transport of BDA.

The present study first confirms that the most extensive innervation of the STN originated from the motor area, as reported extensively in the literature (Hartmann-von Monakow et al., 1978; Kitai and Deniau, 1981; Afsharpour, 1985; Canteras et al., 1988; Bevan et al., 1995; for review, see Parent and Hazrati, 1995), but also from the anterior cingulate cortex (Berendse and Groenewegen, 1991; Maurice et al., 1998). On the other hand, our results, obtained using both anterograde and retrograde tracing methods, demonstrate that the cortical innervation of the STN also originates from the dorsal insular cortex and the most anterior tip of the frontal lobe, both parts of the prefrontal cortex. These projections have each been reported in only one study using anterograde tracer (Afsharpour, 1985; Berendse and Groenewegen, 1991). It is worthy to note that prefrontal areas that project to the STN innervate only a restricted medial region of the STN.

Finally, using both retrograde and anterograde transport methods, we also found evidence that the somatosensory cortex does not project to the STN, in agreement with the views of Afsharpour (1985). The absence of retrograde labeling in the somatosensory cortex could result from insufficient tracer injection in the STN territory that receives inputs from this cortical area. However, in this hypothesis, the globus pallidus, which is known to project topographically to the STN, would not be labeled in its whole extent. Nevertheless, the existence of this projection has been reported by Canteras et al. (1988); however, the data obtained by Canteras et al. (1988) may have been attributable to the somatosensory cortical input to the ventral zone of the zona incerta (Roger and Cadusseau, 1985; Mitrofanis and Mikuletic, 1999).

It has been proposed that the STN represents a second entry of cortical information to the basal ganglia such as the striatum (Nambu et al., 2000). However, although virtually the whole cerebral cortex is known to project to the striatum, only some frontal cortical areas, and mainly the motor cortex, appear to project to the STN. Thus, the STN may represent, in terms of connectivity and function, a different cortical entry from the striatum.

\section{Activity of the corticosubthalamic neurons after dopaminergic denervation}

In the second part of the study, we analyzed the consequences of nigrostriatal denervation on the metabolic activity of the cortico- 
subthalamic neurons identified by WGA-HRP retrograde labeling. This was performed to determine whether this pathway is involved in the altered activity of STN neurons in parkinsonian states. We did not use FG because it is not compatible with cytochrome oxidase in situ hybridization. WGA-HRP was chosen but is known to have a higher propensity for being taken up by fibers of passage than FG. However, the STN is not known to be a structure crossed by fibers of passage originating in the cerebral cortex. Moreover, the pattern of WGA-HRP-positive neurons was similar to that obtained with FG. Thus, it is unlikely that retrogradely labeled neurons were not mainly corticosubthalamic neurons. Nevertheless, we cannot rule out the possibility that the labeling of some of the neurons in both the anterior cingulate and dorsal insular cortices was caused by the slight extension of the injection site into the hypothalamus, which is known to receive inputs from these cortical areas (Floyd et al., 2001).

Metabolic activity was determined using the expression level of COI mRNA. This marker was used because it had already been well validated. Indeed, previous studies showed cytochrome oxidase levels to be regulated by neuronal functional activity (WongRiley and Carroll, 1984; Wong-Riley, 1989) and correlated to $\mathrm{Na}^{+}, \mathrm{K}^{+}-$ATPase activity (Hevner et al., 1992). The latter group has since demonstrated that COI expression is more closely regulated by neuronal activity than the other subunits, particularly nuclear-encoded subunits (Hevner and Wong-Riley, 1993). More recently, the functioning of the basal ganglia in the parkinsonian state was studied using this marker, and the results obtained were in agreement with previous and subsequent results obtained by electrophysiological approaches (Vila et al., 1997, 2000). In addition, the major advantage of this metabolic marker is that it allows an analysis at the cellular level (Hevner and Wong-Riley, 1991) and, in our case, in corticosubthalamic neurons identified by a retrograde tracing method. Yet, we cannot exclude the possibility that the transport of WGA-HRP influences neuronal metabolic activity, and for this reason we did not compare COI mRNA expression between WGA-HRP-labeled and nonlabeled neurons.

The most striking result of this study is that the neurons in the motor and dorsal insular cortex projecting to the STN are hypoactive after dopaminergic denervation. Only a mild decrease in activity was noted in the neurons of the anterior cingulate cortex projecting to the STN. There is no clear demonstration of a relationship between modifications of the metabolic activity of the cell bodies and terminal activity, but variations of COI expression have been shown to be related to electrical activity (Vila et al., 2000). Thus, it is likely that the corticosubthalamic pathway is underactive after dopaminergic denervation. Therefore, cortical neurons projecting to the STN may not simply contribute to the hyperactivity of the STN neurons. Taken in conjunction with previous results (Orieux et al., 2000), our data indicate that the activity of STN neurons in parkinsonian states is regulated by complex influences of glutamatergic hyperactive inputs from the parafascicular nucleus of the thalamus and from the pedunculopontine nucleus and of glutamatergic hypoactive inputs originating in the cerebral cortex. In line with this, it would be interesting to determine whether these opposite influences of the glutamatergic fibers are involved in the changes from a regular pattern of firing in control animals to a bursting activity of STN neurons in parkinsonian syndromes (Bergman et al., 1994; Hassani et al., 1996). Changes in the activity of STN neurons could also result, in part, from changes in STN sensitivity to the influence of its different inputs, as has been suggested recently (Magill et al., 2001).

To the best of our knowledge, this is the first report of a decreased activity of the corticosubthalamic pathway in the parkinsonian state. Several lines of evidence are compatible, however, with a reduction in cortical activity in parkinsonian syndromes. Indeed, a recent study in 6-OHDA-lesioned rats reported a decreased expression of two immediate-early genes (c-fos and zif268), taken as activation markers, in some cortical areas, including the motor and dorsal insular cortex but not the cingulate cortex (Steiner and Kitai, 2001). Similarly, numerous studies using functional imaging in humans have reported impairment of cortical functioning in patients with Parkinson's disease. In particular, a default of activation, reversed by apomorphine, has been described in the supplementary motor area and the prefrontal cortex during movement (Playford et al., 1992; Jahanshahi et al., 1995). However, such studies have to be interpreted carefully because the resolution of the technique used does not discriminate between the specific neuronal populations identified in our study.

The origin of the hypoactivity of cortical neurons projecting to the STN is unknown but may be predicted from the different models of the functional organization of the basal ganglia in parkinsonian syndromes (Albin et al., 1989; DeLong, 1990; Hirsch et al., 2000). Indeed, these models predict a hypoactivity of the excitatory thalamocortical pathway after dopaminergic denervation, which would result in a reduction in cortical activity. Other explanations may also account for a reduced activity of cortical neurons projecting to the STN, such as a direct loss of dopamine stimulation of cortical neurons (Williams and Goldman-Rakic, 1995).

The functional and clinical consequences of the reduced activity of cortical neurons projecting to the STN are difficult to predict. Yet, given their location, they may be involved in motor and cognitive neglect reported in 6-OHDA-lesioned rats (Schwarting and Huston, 1997; Lindner et al., 1999) and in parkinsonian patients. Furthermore, autonomic defects reported in Parkinson's disease (Koike and Takahashi, 1997) may also result partially from the reduced activity of the neurons in the dorsal insular cortex. Should this relationship be confirmed, the corticosubthalamic pathway may represent a new target for improving the symptomatic treatment of Parkinson's disease. Whether deep brain stimulation of the STN, which alleviates the clinical manifestation of the disease, also acts on corticosubthalamic fibers represents a hypothesis worthy of a trial.

\section{REFERENCES}

Afsharpour S (1985) Topographical projections of the cerebral cortex to the subthalamic nucleus. J Comp Neurol 236:14-28.

Albin RL, Young AB, Penney JB (1989) The functional anatomy of basal ganglia disorders. Trends Neurosci 12:366-375.

Benazzouz A, Gross C, Féger J, Boraud T, Bioulac B (1993) Reversal of rigidity and improvement of motor performance by subthalamic highfrequency stimulation in MPTP-treated monkeys. Eur J Neurosci 5:382-389.

Berendse HW, Groenewegen HJ (1991) The connections of the medial part of the subthalamic nucleus in the rat: evidence for parallel organization. In: The basal ganglia III (Bernardi G, Carpenter MB, Di Chiara G, Morelli M, Stanzione P, eds), pp 89-98. New York: Plenum.

Bergman H, Wichmann T, DeLong MR (1990) Reversal of experimental parkinsonism by lesions of the subthalamic nucleus. Science 249:1436-1438.

Bergman H, Wichmann T, Karmon B, DeLong MR (1994) The primate subthalamic nucleus. 2. Neuronal activity in the MPTP model of Parkinsonism. J Neurophysiol 72:507-520.

Bevan MD, Bolam JP (1995) Cholinergic, GABAergic, and glutamate- 
enriched inputs from the mesopontine tegmentum to the subthalamic nucleus in the rat. J Neurosci 15:7105-7120.

Bevan MD, Francis CM, Bolam JP (1995) The glutamate-enriched cortical and thalamic input to neurons in the subthalamic nucleus of the rat: convergence with GABA-positive terminals. J Comp Neurol 361:491-511.

Blanchard V, Chritin M, Vyas S, Savasta M, Feuerstein C, Agid Y, Javoy-Agid F, Raisman-Vozari R (1995) Long-term induction of tyrosine hydroxylase expression: compensatory response to partial degeneration of the dopaminergic nigrostriatal system in the rat brain. J Neurochem 64:1669-1679.

Canteras NS, Shammah-Lagnado SJ, Silva BA, Ricardo JA (1988) Somatosensory inputs to the subthalamic nucleus: a combined retrograde and anterograde horseradish peroxidase study in the rat. Brain Res 458:53-64.

Canteras NS, Shammah-Lagnado SJ, Silva BA, Ricardo JA (1990) Afferent connections of the subthalamic nucleus: a combined retrograde and anterograde horseradish peroxidase study in the rat. Brain Res 513:43-59.

DeLong MR (1990) Primate models of movement disorders of basal ganglia origin. Trends Neurosci 13:281-285.

Féger J, Bevan M, Crossman AR (1994) The projections from the parafascicular thalamic nucleus to the subthalamic nucleus and the striatum arise from separate neuronal populations: a comparison with the corticostriatal and corticosubthalamic afferents in a retrograde fluorescent double-labeling study. Neuroscience 60:125-132.

Floyd NS, Price JL, Ferry AT, Keay KA, Bandler R (2001) Orbitomedial prefrontal cortical projections to hypothalamus in the rat. J Comp Neurol 432:307-328.

François C, Savy C, Jan C, Tandé D, Hirsch EC, Yelnik J (2000) Dopaminergic innervation of the subthalamic nucleus in the normal state, in MPTP-treated monkeys and in Parkinson's disease patients. J Comp Neurol 425:121-129.

Fujimoto K, Kita H (1993) Response characteristics of subthalamic neurons to the stimulation of the sensorimotor cortex in the rat. Brain Res 609:185-192.

Gown AM, Garcia R, Ferguson M, Yamanaka E, Tippens D (1986) Avidin-biotin-immunoglucose oxidase: use in single and double labeling procedures. J Histochem Cytochem 34:403-409.

Guridi J, Herrero MT, Luquin MR, Guillen M, Ruberg M, Laguna J, Vila M, Javoy-Agid F, Agid Y, Hirsch E, Obeso JA (1996) Subthalamotomy in parkinsonian monkeys. Brain 119:1717-1727.

Hartmann-von Monakow K, Akert K, Künzle H (1978) Projections of the precentral motor cortex and other cortical areas of the frontal lobe to the subthalamic nucleus in the monkey. Exp Brain Res 33:395-403.

Hassani O-K, Mouroux M, Féger J (1996) Increased subthalamic neuronal activity after nigral dopaminergic lesion independent of disinhibition via the globus pallidus. Neuroscience 72:105-115.

Hassani O-K, François C, Yelnik J, Féger J (1997) Evidence for a dopaminergic innervation of the subthalamic nucleus in the rat. Brain Res 749:88-94.

Hedreen JC (1999) Tyrosine hydroxylase-immunoreactive elements in the human globus pallidus and subthalamic nucleus. J Comp Neurol 409:400-410.

Herrero MT, Levy R, Ruberg M, Luquin MR, Villares J, Guillen J, Faucheux B, Javoy-Agid F, Guridi J, Agid Y, Obeso JA, Hirsch EC (1996) Consequences of nigrostriatal denervation and 1-dopa therapy on the expression of the glutamic acid decarboxylase messenger RNA in the pallidum. Neurology 47:219-224.

Hevner RF, Wong-Riley MT (1991) Neuronal expression of nuclear and mitochondrial genes for cytochrome oxidase (CO) subunits analyzed by in situ hybridization: comparison with $\mathrm{CO}$ activity and protein. J Neurosci 11:1942-1958.

Hevner RF, Wong-Riley MT (1993) Mitochondrial and nuclear gene expression for cytochrome oxidase subunits are disproportionately regulated by functional activity in neurons. J Neurosci 13:1805-1819.

Hevner RF, Duff RS, Wong-Riley MT (1992) Coordination of ATP production and consumption in brain: parallel regulation of cytochrome oxidase and $\mathrm{Na}+, \mathrm{K}(+)$-ATPase. Neurosci Lett 138:188-192.

Hirsch EC, Perier C, Orieux G, Francois C, Féger J, Yelnik J, Vila M, Levy R, Tolosa ES, Marin C, Trinidad HM, Obeso JA, Agid Y (2000) Metabolic effects of nigrostriatal denervation in basal ganglia. Trends Neurosci 23:S78-S85.

Hutchison WD, Allan RJ, Opitz H, Levy R, Dostrovsky JO, Lang AE, Lozano AM (1998) Neurophysiological identification of the subthalamic nucleus in surgery for Parkinson's disease. Ann Neurol 44:622-628.

Jackson A, Crossman AR (1983) Nucleus tegmenti pedunculopontinus: efferent connections with special reference to the basal ganglia, studied in the rat by anterograde and retrograde transport of horseradish peroxidase. Neuroscience 10:725-765.

Jahanshahi M, Jenkins IH, Brown RG, Marsden CD, Passingham RE, Brooks DJ (1995) Self-initiated versus externally triggered movements. I. An investigation using measurement of regional cerebral blood flow with PET and movement-related potentials in normal and Parkinson's disease subjects. Brain 118:913-933.

Kitai ST, Deniau JM (1981) Cortical inputs to the subthalamus: intracellular analysis. Brain Res 214:411-415.

Koike Y, Takahashi A (1997) Autonomic dysfunction in Parkinson's disease. Eur Neurol 38:8-12.

Lavoie B, Parent A (1990) Immunohistochemical study of the serotoninergic innervation of the basal ganglia in the squirrel monkey. J Comp Neurol 299:1-16.

Lavoie B, Parent A (1994) Pedunculopontine nucleus in the squirrel monkey: projections to the basal ganglia as revealed by anterograde tract-tracing methods. J Comp Neurol 344:210-231.

Limousin P, Pollak P, Benazzouz A, Hoffmann D, Le Bas JF, Broussolle E, Perret JE, Benabid AL (1995) Effect of parkinsonian signs and symptoms of bilateral subthalamic nucleus stimulation. Lancet 345:91-95.

Lindner MD, Cain CK, Plone MA, Frydel BR, Blaney TJ, Emerich DF, Hoane MR (1999) Incomplete nigrostriatal dopaminergic cell loss and partial reductions in striatal dopamine produce akinesia, rigidity, tremor and cognitive deficits in middle-aged rats. Behav Brain Res 102:1-16.

Magill PJ, Bolam JP, Bevan MD (2001) Dopamine regulates the impact of the cerebral cortex on the subthalamic nucleus-globus pallidus network. Neuroscience 106:313-330.

Magnin M, Morel A, Jeanmonod D (2000) Single-unit analysis of the pallidum, thalamus and subthalamic nucleus in parkinsonian patients. Neuroscience 96:549-564.

Maurice N, Deniau JM, Glowinski J, Thierry AM (1998) Relationships between the prefrontal cortex and the basal ganglia in the rat: physiology of the corticosubthalamic circuits. J Neurosci 18:9539-9546.

Mesulam MM (1978) Tetramethyl benzidine for horseradish peroxidase neurohistochemistry: a non-carcinogenic blue reaction-product with superior sensitivity for visualizing neural afferents and efferents. J Histochem Cytochem 26:106-117.

Mitrofanis J, Mikuletic L (1999) Organisation of the cortical projection to the zona incerta of the thalamus. J Comp Neurol 412:173-185.

Mori S, Takino T, Yamada H, Sano Y (1985) Immunohistochemical demonstration of serotonin nerve fibers in the subthalamic nucleus of the rat, cat and monkey. Neurosci Lett 62:305-309.

Mouroux M, Hassani O-K, Féger J (1995) Electrophysiological study of the excitatory parafascicular projection to the subthalamic nucleus and evidence for ipsi- and contralateral controls. Neuroscience 67:399-407.

Nambu A, Tokuno H, Hamada I, Kita H, Imanishi M, Akazawa T, Ikeuchi Y, Hasegawa N (2000) Excitatory cortical inputs to pallidal neurons via the subthalamic nucleus in the monkey. J Neurophysiol 84:289-300.

Naudon L, Raisman-Vozari R, Edwards RH, Leroux-Nicollet I, Peter D, Liu Y, Costentin J (1996) Reserpine affects differentially the density of the vesicular monoamine transporter and dihydrotetrabenazine binding sites. Eur J Neurosci 8:842-846.

Nauta WJH, Mehler WR (1966) Projections of the lentiform nucleus in the monkey. Brain Res 1:3-42.

Orieux G, François C, Féger J, Yelnik J, Vila M, Ruberg M, Agid Y, Hirsch EC (2000) Metabolic activity of excitatory parafascicular and pedunculopontine inputs to the subthalamic nucleus in a rat model of Parkinson's disease. Neuroscience 97:79-88.

Parent A, Hazrati LN (1995) Functional anatomy of the basal ganglia. 2. The place of subthalamic nucleus and external pallidum in basal ganglia circuitry. Brain Res Rev 20:128-154.

Paxinos G, Watson (1998) The rat brain in stereotaxic coordinates. San Diego: Academic.

Playford ED, Jenkins IH, Passingham RE, Nutt J, Frackowiak RS, Brooks DJ (1992) Impaired mesial frontal and putamen activation in Parkinson's disease: a positron emission tomography study. Ann Neurol 32:151-161.

Roger M, Cadusseau J (1985) Afferents to the zona incerta in the rat: a combined retrograde and anterograde study. J Comp Neurol 241 480-492.

Rouzaire-Dubois B, Scarnati E (1987) Pharmacological study of the cortical-induced excitation of subthalamic nucleus neurons in the rat evidence for amino acids as putative neurotransmitters. Neuroscience 21:429-440.

Schwarting RKW, Huston JP (1997) The unilateral 6-hydroxydopamine lesion model in behavioral brain research. Analysis of functional deficits, recovery and treatments. Prog Neurobiol 50:275-331.

Smith Y, Bolam JP, Von Krosigk M (1990) Topographical and synaptic organization of the GABA-containing pallidosubthalamic projection in the rat. Eur J Neurosci 2:500-511.

Smith Y, Bevan MD, Shink E, Bolam JP (1998) Microcircuitry of the direct and indirect pathways of the basal ganglia. Neuroscience $86: 353-387$.

Soghomonian JJ, Chesselet MF (1992) Effects of nigrostriatal lesions on 
the levels of messenger RNAs encoding two isoforms of glutamate decarboxylase in the globus pallidus and entopeduncular nucleus of the rat. Synapse 11:124-133.

Steiner H, Kitai ST (2001) Unilateral striatal dopamine depletion: timedependent effects on cortical function and behavioural correlates. Eur J Neurosci 14:1390-1404.

Sugimoto T, Hattori T, Mizuno N, Itoh K, Sato M (1983) Direct projections from the centre median-parafascicular complex to the subthalamic nucleus in the cat and rat. J Comp Neurol 214:209-216.

Veenman CL, Reiner A, Honig MG (1992) Biotinylated dextran amine as an anterograde tracer for single- and double-labeling studies. J Neurosci Methods 41:239-254.

Vila M, Levy R, Herrero MT, Ruberg M, Faucheux B, Obeso JA, Agid Y, Hirsch EC (1997) Consequences of nigrostriatal denervation on the functioning of the basal ganglia in human and nonhuman primates: an in situ hybridization study of cytochrome oxydase subunit I mRNA. J Neurosci 17:765-773.

Vila M, Perier C, Féger J, Yelnik J, Faucheux B, Ruberg M, RaismanVozari R, Agid Y, Hirsch EC (2000) Evolution of changes in neuronal activity in the subthalamic nucleus of rats with unilateral lesion of the substantia nigra assessed by metabolic and electrophysiological measurements. Eur J Neurosci 12:337-344.

Williams GV, Goldman-Rakic PS (1995) Modulation of memory fields by dopamine D1 receptors in prefrontal cortex. Nature 376:572-575.

Wong-Riley M, Carroll EW (1984) Effect of impulse blockage on cytochrome oxidase activity in monkey visual system. Nature 307:262-264.

Wong-Riley MT (1989) Cytochrome oxidase: an endogenous metabolic marker for neuronal activity. Trends Neurosci 12:94-101. 